\title{
Giant Cell Tumors of Bone in Patients Aged 18 Years Old or Younger: Imaging Features and Tumor Characteristics
}

\author{
Xue-Ping Zhang ${ }^{1, *}$ \\ Xin-Chang $\mathrm{Lu}^{2}$,* \\ Lin-Lin Wang ${ }^{\prime}$ \\ Jie-Qin $W_{e i}{ }^{3}$ \\ Jing Yan' \\ Xiao-Ning Shao' \\ Ying-Yu Che' \\ Jing-Liang Cheng'
}

'Department of Magnetic Resonance Imaging, The First Affiliated Hospital of Zhengzhou University, Zhengzhou, 450052, People's Republic of China; ${ }^{2}$ Department of Orthopedics, The First Affiliated Hospital of Zhengzhou University, Zhengzhou, 450052, People's Republic of China; ${ }^{3}$ Department of Radiology, The First People's Hospital of Nanning, Nanning, 530000, People's

Republic of China

*These authors contributed equally to this work
Correspondence: Jing-Liang Cheng Department of Magnetic Resonance Imaging, The First Affiliated Hospital of

Zhengzhou University, No. I Jianshe East Road, Erqi District, Zhengzhou, 450052,

People's Republic of China

Tel $+86 \quad 13603863860$

Email chengjingliangI868@I63.com
Objective: The majority of giant cell tumors of bone (GCTB) occur in adult patients, especially between the ages of 20 and 40 . This study aims to investigate the imaging features of GCTBs in pediatric patients and compare their characteristics with adult cases.

Methods: Fifty-seven cases of patients aged 18 years old or younger were retrospectively analyzed, accounting for $12.8 \%$ of GCTBs in the First Affiliated Hospital of Zhengzhou University from 2001 to 2019. One hundred twenty-six adult patients (19 years of age and older) with GCTB occurring in long tubular bones were also included in this study. The following clinical information was identified from the medical records: age, sex, and followup data. Imaging features were reviewed by two musculoskeletal radiologists. Patient characteristics and imaging features between the two groups were compared.

Results: A total of 57 patients (32 females, 25 males) were included in the study. The patients' ages ranged from 9 to 18 (median $=17 \mathrm{y}$ ). The majority of tumors occurred in tubular bones $(n=38,66.7 \%)$ and the pelvis $(n=8,14.0 \%)$. Imaging features were identified in GCTB cases occurring in the long tubular bones. Compared with adult GCTB patients, pediatric GCTB patients had a larger superior-inferior $(\mathrm{SI})$ diameter $(\mathrm{P}=0.005)$ and smaller left-to-right diameter/SI diameter ratio $(\mathrm{P}=0.001)$. Epiphyseal involvement was relatively less common in pediatric patients with GCTBs than in adult patients $(\mathrm{P}=0.009)$. The median age of patients without epiphyseal involvement was lower than the median age of patients with epiphyseal involvement (11 vs $17 \mathrm{y}$ ).

Conclusion: GCTB in the pediatric age group is rare. This study has found that, in pediatric patients with GCTBs, the epiphysis is relatively less involved, and the tumor is more likely to grow longitudinally. These findings are helpful in the diagnosis of GCTBs in the pediatric population.

Keywords: giant cell tumors of bone, pediatric, diagnosis, CT, magnetic resonance imaging

\section{Introduction}

Giant cell tumors of bone (GCTB) account for 4-7\% of all primary bone tumors. ${ }^{1-3}$ Although usually benign, GCTBs can be locally aggressive, with occasional malignancy and even lung metastases. According to the fifth edition of the 2020 World Health Organization classification of soft tissue and bone tumors, a GCTB is defined as an intermediate tumor with a locally aggressive biological behavior, but with the potential for distant metastasis. ${ }^{4}$ GCTBs are most common in adults between the ages of 20 and $40 .^{2,5,6}$ The epiphysis or epiphyseal equivalent of long bones is the most common involved anatomical site..$^{2,4,7-11}$ GCTBs are very rare 
below 18 years of age, with an incidence rate of $0.5-$ $10.6 \%$ in Western countries, as previously reported in the literature. ${ }^{1,6,7}$

According to previous reports, epiphyses are not involved in any pediatric GCTB cases, ${ }^{5,11,12}$ which increases the difficulty of diagnosis. In addition, other lesions that commonly occur in this age group, such as chondroblastoma, osteosarcoma, and aneurysmal bone cysts, need to be differentiated from GCTBs.

At present, there are few reports focusing on the imaging characteristics of GCTBs in children and adolescents, and those that do exist are mostly focused on individual cases. Other early published papers, which were limited by imaging techniques at that time, analyzed only X-ray features, excluding computed tomography (CT) and magnetic resonance imaging (MRI) manifestations. ${ }^{1,5,6,11-13}$ To our knowledge, there have been no previous studies comparing GCTB imaging characteristics between children and adults.

In the present study, 57 pediatric cases (18 years old or younger) of pathologically confirmed GCTBs are retrospectively analyzed. The purpose of this study is to analyze the imaging findings of pediatric GCTBs and compare their characteristics with those of adult GCTBs.

\section{Materials and Methods}

\section{Patients}

Between January 2001 and December 2019, a total of 445 patients with histologically confirmed GCTBs were treated surgically at the First Affiliated Hospital of Zhengzhou University. Only cases with pathologically confirmed GCTBs and available imaging data were included in this study. Fifty-seven patients aged 18 or younger were retrospectively analyzed, and their clinical and radiological images were retrieved from the database of our hospital. In addition, 126 adult patients (aged 19 or older) with GCTBs occurring in long tubular bones were included in this study. All the patients in our study underwent radiography, CT, and/or MRI examination before treatment. Medical records were reviewed to obtain demographic information on the patients' age, sex, and follow-up. This study was conducted in accordance with the declaration of Helsinki and approved by the Ethics Committee of the First Affiliated Hospital of Zhengzhou University. Written informed consent was obtained from the participants or the guardian of the participants.

\section{Imaging Procedures}

Patients routinely underwent anterior-posterior and lateral plain radiographs of the diseased region using several kinds of X-ray devices. CT scans were obtained using a 16-row (Siemens Medical Solutions, Erlangen, Germany) or 64-row (LightSpeed VCT, General Electric Medical Systems, Milwaukee, WI, USA) CT scanner. Bone and soft tissue windows and sagittal and coronal reconstruction images were performed to confirm observations. MRI examinations were performed with a 3.0T magnetic resonance (MR) scanner (Magnetom Skyra, Siemens Medical Solutions, Erlangen, Germany) with an appropriate surface coil or a joint coil. Axial, sagittal, and coronal images were obtained using the following sequences: turbo spin echo (TSE) $T_{1}$-weighted imaging $\left(T_{1} \mathrm{WI}\right)$, TSE $T_{2}$-weighted imaging $\left(T_{2} \mathrm{WI}\right)$, and TSE $T_{2}$ WI with fat suppression. Contrast-enhanced images were obtained using $T_{l}$ WI. The field of view, slice thickness, and interslice gap were determined by the location and size of the lesion.

\section{Imaging Analysis}

All the imaging manifestations were reviewed independently by two musculoskeletal radiologists. When diagnostic outcomes were different, consensus was reached after discussion. The radiographic findings were identified, including location, skeletal maturity, tumor size, expansibility, peripheral sclerotic rim, cortical bone destruction, periosteal reaction, soft tissue extension, cystic changes, fluid-fluid levels, and pathologic fracture.

Radiography and CT examination were more advantageous for the observation of expansibility, the peripheral sclerotic rim, cortical bone destruction, periosteal reaction, and pathologic fracture, while MRI was sensitive to soft tissue extension, cystic changes, and fluid-fluid levels.

Tumor size was established on MR or CT imaging by considering its longest diameter. According to the aforementioned imaging features, including expansibility, the peripheral sclerotic rim, cortical bone destruction, periosteal reaction, soft tissue extension, cystic changes, fluidfluid levels, and pathologic fracture, GCTBs were classified into positive and negative groups.

\section{Pathology}

Histological slides obtained from the curettage and resection specimens of the pediatric and adult GCTB patients in this study were reviewed by bone pathologists to confirm 
the diagnosis. When histologic features were atypical, immunohistochemistry (IHC) was used to further confirm the diagnosis of the sections, including the RANKL, RANK, VEGF, MMP-9, and Ki-67 protein expressions. H3F3A and H3F3B mutation analyses were also applied to further confirm the diagnosis when necessary.

\section{Treatment}

None of the patients had undergone other treatment before surgery. Patients underwent intralesional curettage or enbloc resection by senior orthopedic surgeons.

\section{Statistical Analysis}

Patient characteristics and imaging features were presented as absolute numbers and percentages or as mean \pm standard deviation. A chi-square test or Fisher's exact test was used to compare the composition ratio of patient characteristics and tumor imaging features between the pediatric patient group and the adult patient group. A $t$-test was performed to compare the differences in tumor length between the two groups, including left-to-right (LR) diameter, superior-inferior (SI) diameter, and LR diameter/SI diameter. Statistical analyses were performed using SPSS software (IBM SPSS Statistics for Windows, Version 22.0, IBM Corporation, Armonk, USA). All statistical tests were two-sided, with $P<0.05$ considered as statistically significant.

\section{Results}

\section{Clinical Features}

Of the 445 patients with GCTBs, 57 under the age of 18 were identified, an incidence of $12.8 \%$. Of these patients, $32(56.0 \%)$ were girls and $25(44.0 \%)$ were boys, with ages ranging from 9 to 18 (median $=17 \mathrm{y}$ ). Anatomical sites included the long tubular bones $(\mathrm{n}=34,59.6 \%, 13$ cases in the tibia, 7 cases in the femur, 7 cases in the radius, 5 cases in the fibula, 2 cases in the humerus); the short tubular bones ( $\mathrm{n}=4,7.0 \%, 2$ cases in the metacarpal, 1 case in the phalanx, 1 case in the metatarsus); the vertebral body $(\mathrm{n}=2,3.5 \%, 1$ case in the cervical spine, 1 case in the lumbar spine); the pelvis ( $\mathrm{n}=8,14.0 \%, 6$ cases in the sacrum, 1 case in the acetabulum, 1 case in the ischium); the patella $(\mathrm{n}=4,7.0 \%)$; and one each $(1.8 \%)$ in the femoral head, sternum, scapula, and calcaneus. One patient $(1.8 \%)$, an 18-year-old girl, had multifocal disease with involvement of the proximal and distal tibia, distal femur, and talus. The age distribution is shown in Figure 1, and the location distribution is summarized in Table 1.

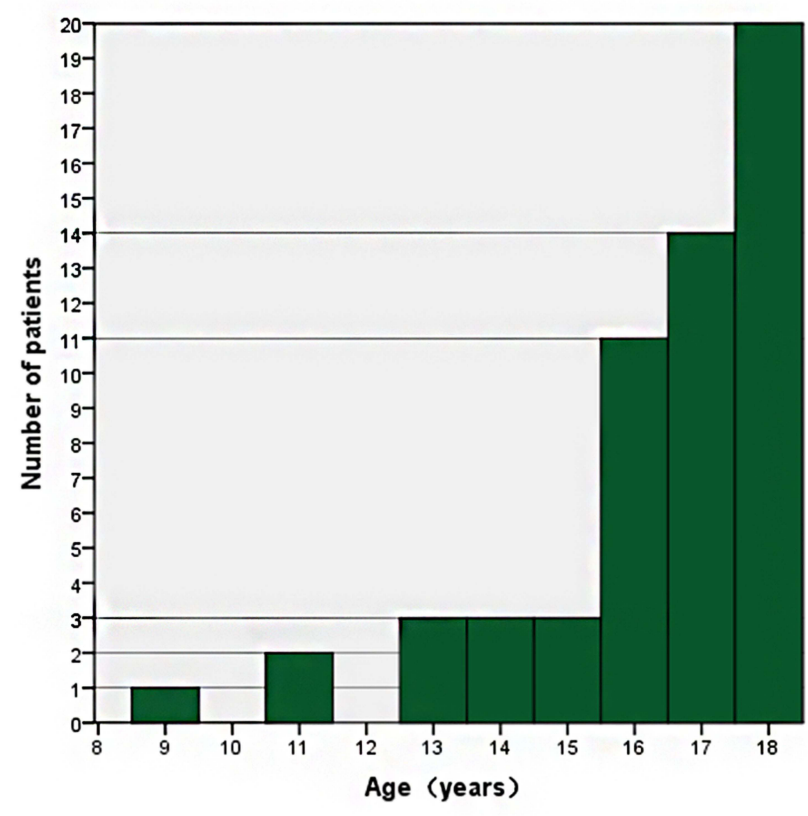

Figure I The distribution of age in 57 patients with giant cell tumors 18 years of age and younger.

In addition, 126 adult patients with GCTBs occurring in long tubular bones were included in this study (60 women and 66 men, average age of 34, age range of 18 64 , median age of 29). Radiological images were available for review in all of the adult cases.

\section{Radiological Findings Imaging Features}

Most pediatric GCTB cases were located in the long tubular bones $(n=34,59.6 \%)$. These were good anatomical sites for observing tumor locations (eg, epiphysis or metaphysis), so our study chose mainly GCTB cases occurring in the long tubular bones to analyze imaging features.

All 34 pediatric GCTBs located in the long tubular bones underwent radiography and plain $\mathrm{CT}$ scans before treatment or intervention, of which 30 received contrastenhanced CT. MRI was performed on 21 patients, of which 15 underwent contrast-enhanced scanning.

The most common sites of the lesions were the tibia, femur, and radius (Table 1). All 34 GCTBs located in the long tubular bones showed an osteolytic pattern of destruction of the bone, with a narrow zone of transition or sclerotic margin. Various degrees of bone expansion were present in most patients. Some cases demonstrated locally aggressive behavior, which led to cortical bone destruction, periosteal reaction, and soft tissue extension. Cystic changes and fluid-fluid levels were visible on CT and/or 
Table I Location of Giant Cell Tumors (GCTBs) in 57 Patients 18 Years of Age and Younger

\begin{tabular}{|c|c|c|c|}
\hline Location & $\begin{array}{c}\text { Number } \\
\text { of } \\
\text { Cases(\%) }\end{array}$ & Proximal & Distal \\
\hline Long tubular bone & $34(59.6 \%)$ & & \\
\hline Tibia & 13 & 11 & 2 \\
\hline Femur & 7 & 7 & \\
\hline Radius & 7 & & 7 \\
\hline Fibula & 5 & 5 & \\
\hline Humerus & 2 & 2 & \\
\hline Short tubular bone & $4(7.0 \%)$ & & \\
\hline Metacarpal & 2 & 1 & I \\
\hline Phalanx(finger) & I & I & \\
\hline Metatarsus & 1 & I & \\
\hline Pelvis & $8(\mid 4.0 \%)$ & & \\
\hline Sacrum & 6 & & \\
\hline Acetabulum & I & & \\
\hline Ischium & I & & \\
\hline Patella & $4(7.0 \%)$ & & \\
\hline Vertebral body & $2(3.5 \%)$ & & \\
\hline Cervical spine & I & & \\
\hline Lumbar spine & I & & \\
\hline Femoral head & $\mathrm{I}(\mathrm{I} .8 \%)$ & & \\
\hline Sternum & $\mathrm{I}(\mathrm{I} .8 \%)$ & & \\
\hline Scapula & $\mathrm{I}(\mathrm{I} .8 \%)$ & & \\
\hline Calcaneus & $\mathrm{I}(\mathrm{I} .8 \%)$ & & \\
\hline $\begin{array}{l}\text { Multifocal disease(proximal and } \\
\text { distal tibia, distal femur and } \\
\text { talus) }\end{array}$ & $\mathrm{I}(\mathrm{I} .8 \%)$ & & \\
\hline Total & 57 & & \\
\hline
\end{tabular}

MR images in some cases. Pathologic fracture was identified in four cases (Figure 2).

In the short tubular bones and smaller long tubular bones, such as the radius, fibula, and metacarpals, lesions generally showed prominent expansion of the bone and tended to be located centrally.

Patient characteristics and imaging features (including the positive rates) of pediatric GCTB cases located in the long tubular bones are detailed in Table 2.

\section{Characteristics of GCTB Patients Under 18 and Adult Patients}

As with the pediatric cases, 126 adult patients with GCTBs in the long tubular bones underwent radiography and plain
CT scans, of which 105 received CT enhancement and 62 received non-enhanced and/or enhanced MRI. Patient characteristics and the positive rates of image features are detailed in Table 2.

We compared the characteristics of 34 pediatric GCTB patients and 126 adult GCTB patients. All the tumors occurred in the long tubular bones of the extremities. Significant differences were found in the tumor SI diameter $(\mathrm{P}=0.005)$ and LR diameter/SI diameter $(\mathrm{P}=$ 0.001 ) between the two groups. Compared with adult GCTB patients, pediatric GCTB patients had a larger SI diameter and smaller LR diameter/SI diameter. Our data showed that $8.8 \%$ of GCTBs arising in long tubular bones lacked epiphyseal involvement, while all adult GCTBs involved the epiphysis (100\%). This result was statistically significant $(\mathrm{P}=0.009)$. The two groups were similar with regard to gender, location, expansibility, peripheral sclerotic rim, cortical bone destruction, periosteal reaction, soft tissue extension, cystic changes, fluid-fluid levels, and pathologic fracture $(\mathrm{P}>0.05$, Table 2$)$.

\section{Evaluation of Skeletal Maturity and Epiphyseal Involvement}

The 36 pediatric GCTB cases located in the long and short tubular bones that had radiological images for review were evaluated for skeletal maturity and to identify whether the epiphysis or epiphyseal equivalent of the bone was involved (Tables 2-4).

The evaluation of skeletal maturity revealed six cases with open physes (17\%) and 30 with closed growth plates $(83 \%)$. Epiphyseal involvement was found in all the cases with closed growth plates, while tumors extending into the epiphysis were found in half the cases with open physes. In the cases with open physes, the patients were younger (median age $=13 \mathrm{y}$ ) and most cases were male, while in cases with closed growth plates, patients were older (median age $=17 \mathrm{y}$ ) and most cases were female (Table 3 ).

The meta-epiphyseal area of the tubular bones was the anatomical site where GCTBs commonly arose. Thirtythree cases (92\%) involved the metaphysis and epiphysis (aged 13-18 y, median $=17 \mathrm{y}$ ); most of the epiphysis was involved in 32 cases, and epiphyseal involvement was minimal in only 1 case. Three cases (8\%) involved the metaphysis without invasion of the epiphysis (aged 9-13 $\mathrm{y}$, median $=11 \mathrm{y}$, Figure 3), and there were no lesions involving the epiphysis alone (Table 4). Due to the small number of cases, these data are not suitable for statistical 

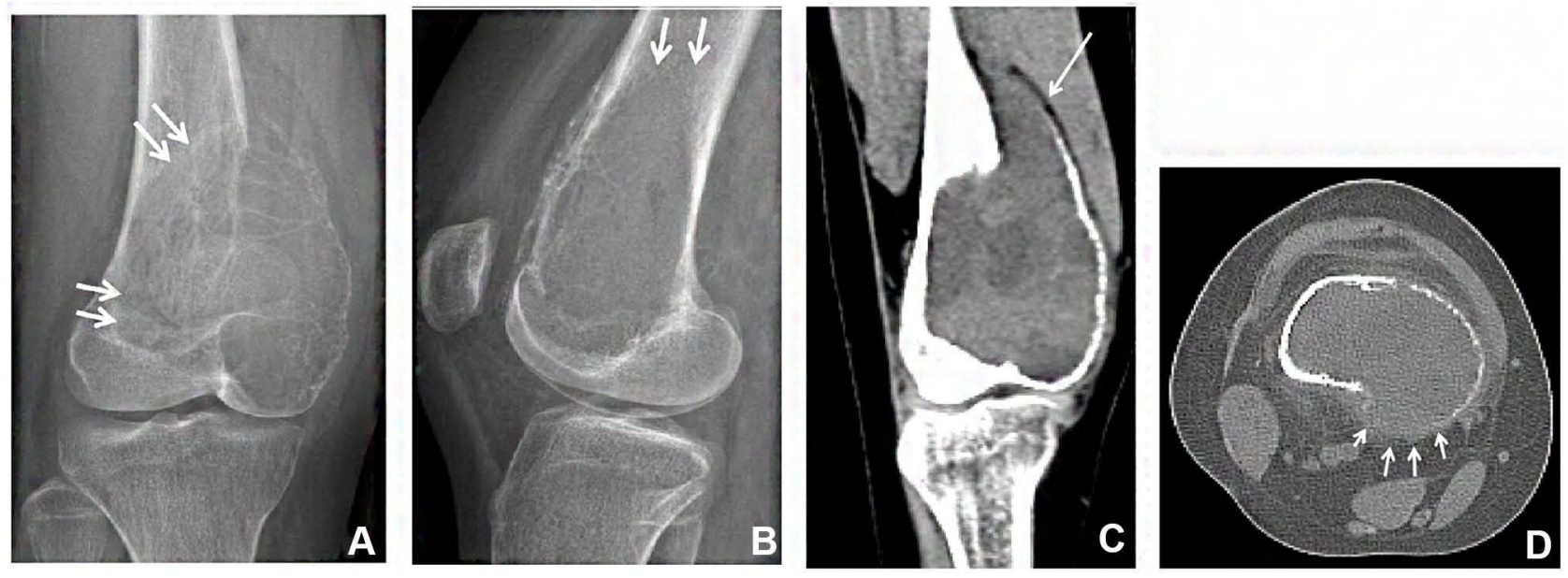

Figure 2 A skeletally mature 16-year-old girl with GCTB in the distal femur. Plain radiographs (A and B) of the knee demonstrate an eccentric expansile osteolytic lesion involving the distal femoral epiphysis and metaphysis. The lesion is well defined with a narrow zone of transition (arrow). CT (C and D) showed focal loss of bone cortex and adjacent soft tissue extension (arrow).

analysis. The age range of patients with epiphyseal involvement was 13-18 with a median age of 17 , while in patients without epiphyseal involvement, the age range was 9-13 with a median age of 11 (Table 4).

\section{Pathology}

Of the 57 cases with pediatric GCTBs, 30 cases with typical morphologic patterns were diagnosed by conventional histopathology, and 27 cases received an additional IHC examination to further confirm the diagnosis, of which 3 cases received $\mathrm{H} 3 \mathrm{~F} 3 \mathrm{~A}$ and $\mathrm{H} 3 \mathrm{~F} 3 \mathrm{~B}$ mutation analysis.

\section{Treatment}

Most of the pediatric GCTB patients underwent intralesional curettage $(n=41)$, while some cases $(n=16)$ located in the smaller long bones and short tubular bones, such as the fibula, radius, and metacarpals, were treated with an en-bloc resection.

\section{Discussion}

GCTBs are considerably less common in the pediatric population (18 years old or younger), and this diagnosis is often not considered, especially in skeletally immature patients with open physes. In this study, we analyzed demographic data, anatomical distribution, and imaging findings of 57 cases of pediatric GCTB patients. At the same time, the characteristics of pediatric and adult patients with GCTBs in the long tubular bones were compared to find whether differences existed between the two groups.
Compared with the incidence rate reported in previous literature (which ranges between $1.7 \%$ and $10.6 \%$ ), ${ }^{5,6,12,13}$ the present study demonstrates a higher incidence rate of $12.8 \%$ (57/445 patients). This study includes all GCTB patients 18 years old or younger, including patients with open physes and closed growth plates, while only skeletally immature patients with open physes had been included in some previous studies. ${ }^{5,12,13}$ This may explain the reason for the higher incidence rate to some extent.

In the present study, the female distribution is $56 \%$, which is a little lower than the range reported in the literature $(60 \%-82 \%){ }^{1,6,11,12,14}$ In our study, the age of the patients ranged from 9 to 18 (median $=17 \mathrm{y}$ ), and the majority of cases were between 16 and 18 years old $(\mathrm{n}=$ $45,78.9 \%$ ), which is consistent with previous studies. ${ }^{11,12}$ The majority of the lesions were located in the long tubular bones $(59.6 \%)$, including the tibia $(22.8 \%)$, followed by the femur and radius $(12.3 \%$ each), the fibula $(8.8 \%)$, and humerus (3.5\%), which is similar to those reported in other pediatric and adult studies. $6,11,13,14$

Imaging plays an important role in the diagnosis of GCTBs. X-ray, CT, and MRI are common imaging examination methods used to reach a diagnosis. To the best of our knowledge, the CT and MRI features of GCTBs in pediatric patients have not been extensively evaluated. In addition, the imaging features of GCTBs in children and adults have not been compared in previous literature.

In this study, all the lesions located in the long and short tubular bones that had radiological images for review showed an osteolytic pattern of destruction of the bone, with a narrow zone of transition or sclerotic margin. 
Table 2 Patient Characteristics and Imaging Features of Pediatric (18 Years of Age and Younger) and Adult (Over 18 Years) Patients with GCTB Occurring in Long Tubular Bones

\begin{tabular}{|c|c|c|c|}
\hline Parameters & $\begin{array}{c}\text { Pediatric } \\
\text { GCTB } \\
\text { Patients(\%) }\end{array}$ & $\begin{array}{c}\text { Adult } \\
\text { GCTB } \\
\text { Patients(\%) }\end{array}$ & $P$ value \\
\hline $\begin{array}{l}\text { Sex } \\
\qquad \text { Male } \\
\text { Female }\end{array}$ & $\begin{array}{l}14(42) \\
20(58)\end{array}$ & $\begin{array}{l}60(48) \\
66(52)\end{array}$ & 0.504 \\
\hline $\begin{array}{l}\text { Extent of involvement of } \\
\text { bones }\end{array}$ & 34 & 126 & 0.009 \\
\hline Metaphysis and epiphysis & 31 (91.2) & $126(100 \%)$ & \\
\hline Metaphysis without epiphysis & $3(8.8)$ & 0 & \\
\hline $\begin{array}{l}\text { Location } \\
\text { Tibia } \\
\text { Femur } \\
\text { Radius } \\
\text { Fibula } \\
\text { Humerus } \\
\text { Ulna }\end{array}$ & $\begin{array}{l}13 \\
7 \\
7 \\
5 \\
2 \\
0\end{array}$ & $\begin{array}{c}41 \\
41 \\
16 \\
6 \\
6 \\
16\end{array}$ & 0.609 \\
\hline $\begin{array}{l}\text { Tumor length } \\
\text { LR diameter }(\mathrm{cm}) \\
\text { SI diameter }(\mathrm{cm}) \\
\text { LR diameter/ SI diameter }\end{array}$ & $\begin{array}{c}4.0 \pm 1.2 \\
6.6 \pm 2.7 \\
0.64 \pm 0.17\end{array}$ & $\begin{array}{c}3.8 \pm 1.2 \\
4.8 \pm 1.3 \\
0.80 \pm 0.16\end{array}$ & $\begin{array}{l}0.519 \\
0.005 \\
0.001\end{array}$ \\
\hline $\begin{array}{l}\text { Expansion, n (\%) } \\
\text { Yes } \\
\text { No }\end{array}$ & $\begin{array}{l}18(52.9) \\
16(47.1)\end{array}$ & $\begin{array}{l}54(42.5) \\
72(57.5)\end{array}$ & 0.294 \\
\hline $\begin{array}{l}\text { Peripheral rim of sclerosis, } \\
\text { n (\%) } \\
\text { Yes } \\
\text { No }\end{array}$ & $\begin{array}{l}14(4 \mid .2) \\
20(58.8)\end{array}$ & $\begin{array}{l}54(42.9) \\
72(57.1)\end{array}$ & 0.860 \\
\hline $\begin{array}{l}\text { Cortical bone destruction, } \\
\text { n (\%) } \\
\text { Yes } \\
\text { No }\end{array}$ & $\begin{array}{l}20(58.8) \\
14(4 \mid .2)\end{array}$ & $\begin{array}{l}66(52.5) \\
60(47.5)\end{array}$ & 0.504 \\
\hline $\begin{array}{l}\text { Periosteal reaction, } \mathrm{n}(\%) \\
\text { Yes } \\
\text { No }\end{array}$ & $\begin{array}{c}3(8.8) \\
31(91.2)\end{array}$ & $\begin{array}{l}13(10) \\
113(90)\end{array}$ & 1.000 \\
\hline $\begin{array}{l}\text { Soft tissue extension, n (\%) } \\
\text { Yes } \\
\text { No }\end{array}$ & $\begin{array}{l}10(29.4) \\
24(70.6)\end{array}$ & $\begin{array}{l}54(42.5) \\
72(57.5)\end{array}$ & 0.156 \\
\hline $\begin{array}{l}\text { Cystic change, n (\%) } \\
\text { Yes } \\
\text { No }\end{array}$ & $\begin{array}{l}20(58.8) \\
14(41.2)\end{array}$ & $\begin{array}{l}69(55) \\
57(45)\end{array}$ & 0.672 \\
\hline $\begin{array}{l}\text { Fluid-fluid level, n (\%) } \\
\text { Yes } \\
\text { No }\end{array}$ & $\begin{array}{l}6(17.6) \\
28(82.4)\end{array}$ & $\begin{array}{l}16(12.5) \\
110(87.5)\end{array}$ & 0.457 \\
\hline
\end{tabular}

(Continued)
Table 2 (Continued).

\begin{tabular}{|l|c|c|c|}
\hline Parameters & $\begin{array}{c}\text { Pediatric } \\
\text { GCTB } \\
\text { Patients(\%) }\end{array}$ & $\begin{array}{c}\text { Adult } \\
\text { GCTB } \\
\text { Patients(\%) }\end{array}$ & P value \\
\hline $\begin{array}{l}\text { Pathologic fracture } \\
\text { Yes }\end{array}$ & $4(11.8)$ & $13(10)$ & 1.000 \\
No & $30(88.2)$ & $113(90)$ & \\
\hline
\end{tabular}

Abbreviations: LR, left and right; $\mathrm{Sl}$, superior and inferior.

Calcification was not seen in all the lesions, and varying degrees of eccentric expansion of the bone were present in most patients. Expansion of the bone is related to the chronic course of the tumor, indicating that the tumor is less aggressive and tumor growth is relatively slow. The positive rate of expansibility of the long tubular bones in our study was $52.9 \%$, which was similar to those in previous reports. ${ }^{15}$ In the cases in the present study, the lesions located in the slender and smaller tubular bones, such as the radius, fibula, phalanx, and metacarpals, showed prominent expansion of the bone and tended to be located centrally, similar to what has been reported in other pediatric studies. ${ }^{13}$

The peripheral sclerotic rim is considered to be a protective factor for tumor growth and local invasion. In this study, it was more easily observed on CT and mostly appeared as a thin and incomplete sclerotic rim around the tumor. In previous GCTB studies, it was believed that a peripheral sclerotic rim around a tumor was rare; ${ }^{16}$ however, our study demonstrated that it had a positive rate of $41.2 \%$. This higher positive rate may be due to the high spatial resolution of CT, as the peripheral sclerotic rim is more easily observed by $\mathrm{CT}$ than by radiography.

GCTBs can be locally aggressive. The tumors continue to grow, which may eventually cause destruction to the cortical bone, soft tissue invasion, and even soft tissue masses. In our study, the positive rates for cortical bone destruction and soft tissue extension of the long tubular bones were $58.8 \%$ and $29.4 \%$ respectively. Cortical bone destruction could be detected by CT or MRI, which manifests as a high-density cortical interruption on the $\mathrm{CT}$ and incomplete low-signal margins on the MRI.

Soft tissue extension was displayed in both CT and MRI. With a high soft tissue resolution, MRI can better identify soft tissue extension and soft tissue mass. 
Table 3 Evaluation of Skeletal Maturity of GCTB Patients 18 Years of Age and Younger

\begin{tabular}{|l|c|c|c|c|}
\hline & Number(\%) & Age Range (Median) & Sex (M/F) & Epiphysis Involvement $\mathbf{n}(\%)$ \\
\hline Patients with open physes & $6(17)$ & $9-16(13)$ & $5 / 1$ & $3(50)$ \\
Patients with closed growth plates & $30(83)$ & $14-18(17)$ & $11 / 19$ & $30(100)$ \\
\hline
\end{tabular}

Abbreviations: F, female; M, male.

Table 4 GCTBs in Patients 18 Years of Age and Younger: Extent of Involvement of the Lesions in Long and Short Tubular Bones

\begin{tabular}{|l|c|c|c|}
\hline Extent of Involvement & Number of Patients(\%) & Age Range (y) & Median Age (y) \\
\hline Metaphysis and epiphysis & $33(92)$ & $13-18$ & 17 \\
Metaphysis without epiphysis & $3(8)$ & $9-13$ & 11 \\
Epiphysis & 0 & & \\
\hline
\end{tabular}

A periosteal reaction suggests new bone formation, which is very rare in GCTB cases. The incidence of periosteal reaction in long tubular bones in our study was quite low ( $\mathrm{n}=3,8.8 \%$ ), which is consistent with previous reports. ${ }^{13,16,17}$ As the GCTB stroma contains abundant vessels, cystic changes, necrosis, and hemorrhage can be observed in the MRI. ${ }^{16,18}$

Previous studies have found that the recurrence rate of GCTBs with cystic changes is high, and cystic changes were disclosed as an independent risk factor for recurrence after surgery. ${ }^{15}$ Fluid-fluid levels are a typical sign of hemorrhage in the tumor, which occurs due to the hemorrhage layer. MRI was very sensitive to cystic changes and fluid-fluid levels, which manifested as the homogenous high-signal intensity and high-iso/low-signal fluid-fluid levels on the $T_{2}$ WI image. In our study, the positive rate of cystic changes in long tubular bones was $58.8 \%$, which is similar to that of previous reports. ${ }^{15}$ The fluid-fluid levels of long tubular bones were seen in only six cases $(17.6 \%)$. This may be because the scan time, especially the CT scan time, was not long enough to form a hemorrhage layer.

In the cases in our study, pathologic fracture was present in $11.8 \%(4 / 34)$ of lesions, which is comparable to previous reports of GCTBs in the pediatric population (13\%) and GCTBs arising in the conventional age range (5-10\%). ${ }^{9,11,19,20}$

To our knowledge, multifocal GCTBs are extraordinarily rare. ${ }^{12,21-23}$ In the present study, one GCTB in an 18year-old girl showed multifocal lesions with an osteolytic
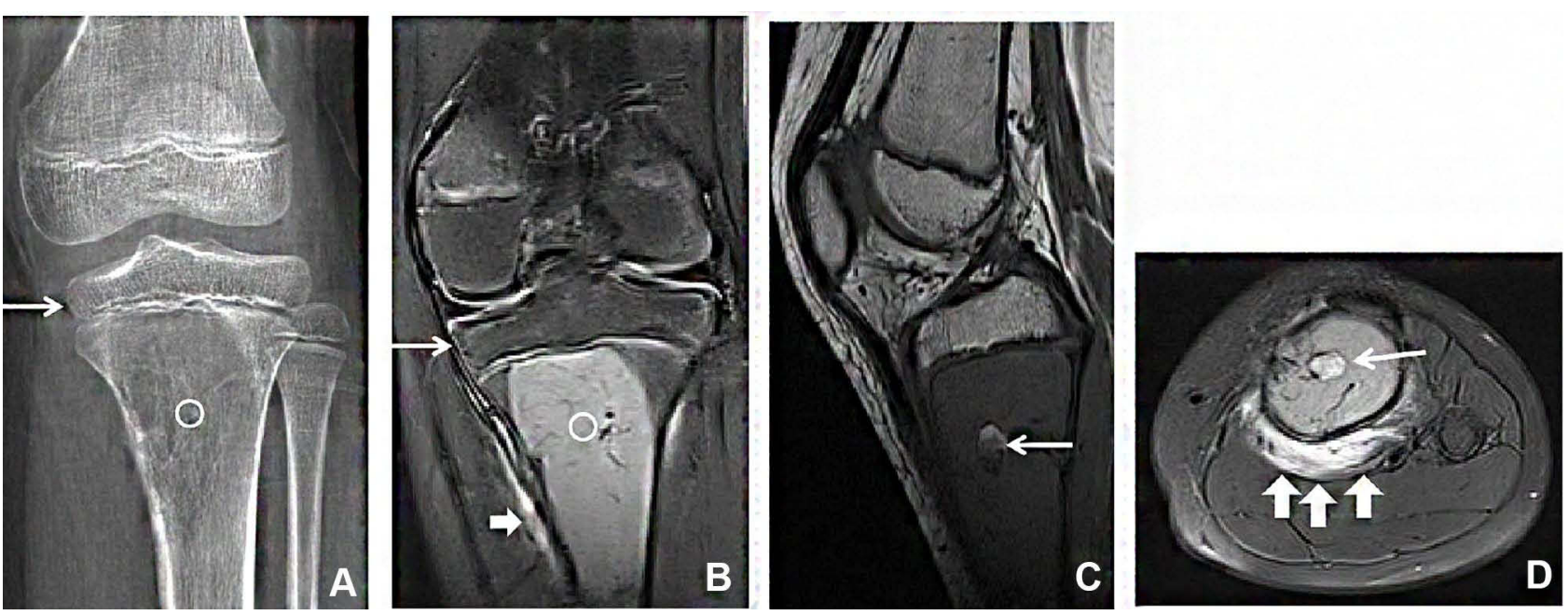

Figure 3 A skeletally immature 9-year-old girl with GCTB in the proximal tibia. Plain radiograph (A) demonstrates an osteolytic lesion (white circle) centered in the metadiaphysis, sparing the epiphysis (arrow in a). Coronal fat-suppressed $T_{2}(\mathbf{B})$, sagittal $T_{I}(\mathbf{C})$, and axial fat-suppressed $T_{2}(\mathbf{D})$ show a solid lesion (white circle) in the proximal tibial metadiaphysis with sparing of the epiphysis (arrow in b). The lesions were mainly solid, with a few cystic components (arrows in c and d). Adjacent soft tissue edema were shown on coronal and axial $T_{2} \mathrm{WI}$ (thick arrows in $\mathrm{b}$ and $\mathrm{d}$ ). 
pattern of destruction of the bone involving the proximal and distal tibia, distal femur, and talus.

Some studies have shown that the biological behavior of GCTBs in pediatric patients does not appear to be significantly different from that reported in adults. ${ }^{1}$ However, previous studies have not compared the imaging features of GCTBs in children and adults in detail. In our study, compared with adult GCTB patients, pediatric GCTB patients had a larger SI diameter and smaller LR diameter/SI diameter $(\mathrm{P}<0.05$, Table 2$)$, which suggested that in the pediatric population with GCTBs, tumors tend to grow longitudinally. Our data shows that $8.8 \%$ of pediatric GCTBs in long tubular bones lacked epiphyseal involvement, while all adult GCTBs involved the epiphysis $(100 \%)$. This result was statistically significant $(\mathrm{P}=$ 0.009). These findings may be helpful in the diagnosis of GCTBs in children.

Other imaging characteristics of the GCTBs in this study were similar to those found in adult patients, including gender, the osteolytic pattern of destruction of the bone, the incidence rates of expansibility, peripheral sclerotic rims, cortical bone destruction, periosteal reaction, soft tissue extension, cystic changes, fluid-fluid levels, and pathologic fracture $(\mathrm{P}>0.05$, Table 2$)$.

In the present study, most cases $(83 \%)$ were patients with closed growth plates nearing skeletal maturity, with only $17 \%$ with open physes. This could be because the patients in our study were relatively older, mostly between the ages of 16 and 18. The median age of patients with open physes was 13 compared with 17 for patients with closed growth plates. Among the patients with open physes, boys were more common, which may be related to the phenomenon of skeletal development in female adolescents being earlier than in males. ${ }^{24}$

Picci et $\mathrm{al}^{5}$ reported that five of the six skeletally immature patients with GCTBs in their study had tumors that penetrated the epiphyseal growth plate and involved the epiphysis, suggesting that the tumors had aggressive behavior. The study of GCTBs in children and adolescents conducted by Puri et al ${ }^{12}$ showed 13 out of 15 tumors in tubular bones with open growth plates extended to the epiphysis. Our data demonstrated that three of the six GCTB patients with open physes had epiphyseal involvement, suggesting that the open growth plates did not seem to prevent GCTBs from infringing upon the epiphyseal cartilage and epiphysis, which is in accordance with previous reports.
Although the meta-epiphyseal area of the tubular bones was the most common site for GCTBs to arise in this study, we still found that $8 \%$ of cases involved the metaphysis, sparing the epiphysis. In contrast, of the 126 adult GCTB cases located in the long tubular bones, all demonstrated the involvement of the epiphysis. This result was in accordance with previous reports. ${ }^{9-11,19,25}$ Al-Ibraheemi et a ${ }^{11}$ reported that $21 \%$ of pediatric GCTBs arising in tubular bones lacked epiphyseal involvement, and Picci et $\mathrm{al}^{5}$ mentioned that epiphyseal involvement was less common in children, suggesting that GCTBs originated in the metaphysis. In our study, the median age of patients without epiphyseal involvement was 11 years old, which was significantly less than the median age (17 y) of patients with epiphyseal involvement. This result suggests that epiphyseal involvement in tubular bones is closely related to a patient's age and is relatively uncommon in younger patients with GCTBs.

GCTBs usually involve the epiphysis or epiphyseal equivalent, with a peak incidence in adults aged between 20 and 40. When the tumor occurs in the pediatric age group, especially if the epiphysis is not involved, the GCTB diagnosis becomes more difficult. In addition, the imaging findings of GCTBs may overlap with other benign (aneurysmal cysts, chondroblastoma) and malignant (osteosarcoma, Ewing's sarcoma) bone tumors, increasing the difficulty of preoperative diagnosis. ${ }^{26}$

Our study has several limitations. First, since this was a retrospective study, the imaging data were not collected with a standard scan protocol, which might affect the observation of imaging findings. Second, due to the small number of patients, the impact of the statistical analysis is limited. In future research, multi-center cooperation is required to include a larger sample size to confirm the findings of this study.

In summary, GCTBs are rare in the pediatric age group. Most of the imaging features of GCTBs in the pediatric population were similar to those in the adult population. However, epiphyseal involvement was less common in pediatric patients, especially in younger children who still had open epiphyseal growth plates. Moreover, compared with adult patients, it was found that tumors were more likely to grow longitudinally in pediatric patients. The above differences can facilitate the diagnosis of GCTBs in pediatric patients.

\section{Disclosure}

The authors declare that there is no conflict of interest. 


\section{References}

1. Strom TM, Skeie AT, Lobmaier IK, Zaikova O. Giant cell tumor: a rare condition in the immature skeleton-a retrospective study of symptoms, treatment, and outcome in 16 children. Sarcoma. 2016;2016:3079835.

2. Xu W, Li X, Huang W, et al. Factors affecting prognosis of patients with giant cell tumors of the mobile spine: retrospective analysis of 102 patients in a single center. Ann Surg Oncol. 2013;20(3):804-810. doi:10.1245/s10434-012-2707-6

3. Amanatullah DF, Clark TR, Lopez MJ, et al. Giant cell tumor of bone. Orthopedics. 2014;37(2):112-120. doi:10.3928/0147744720140124-08

4. Choi JH, Ro JY. The 2020 WHO classification of tumors of bone: an updated review. Adv Anat Pathol. 2021;28(3):119-138. doi:10.1097/ PAP.0000000000000293

5. Picci P, Manfrini M, Zucchi V, et al. Giant-cell tumor of bone in skeletally immature patients. $J$ Bone Joint Surg Am. 1983;65:486-490. doi:10.2106/00004623-198365040-00009

6. Schutte HE, Taconis WK. Giant cell tumor in children and adolescents. Skeletal Radiol. 1993;22::173-176. doi:10.1007/ BF00206148

7. Lin F, Hu Y, Zhao L, et al. The epidemiological and clinical features of primary giant cell tumor around the knee: a report from the multicenter retrospective study in China. $J$ Bone Oncol. 2016;5:38-42. doi:10.1016/j.jbo.2016.02.001

8. Unni KK, Inwards CY. Dahlin's Bone Tumors: General Aspects and Data on 11087 Cases. Philadelphia, PA: Lippincott Williams \& Williams; 2010:179-183, 310-316.

9. Campanacci M, Baldini N, Boriani S, et al. Giant-cell tumor of bone. J Bone Joint Surg Am. 1987;69:106-114. doi:10.2106/00004623198769010-00018

10. Dahlin DC. Caldwell lecture. Giant cell tumor of bone: highlights of 407 cases. AJR Am J Roentgenol. 1985;144:955-960. doi:10.2214/ ajr.144.5.955

11. Al-Ibraheemi A, Inwards CY, Zreik RT, et al. Histologic spectrum of Giant Cell Tumor (GCT) of bone in patients 18 years of age and below: a Study of 63 Patients. Am J Surg Pathol. 2016;40 (12):1702-1712. doi:10.1097/PAS.0000000000000715

12. Puri A, Agarwal MG, Shah M, Jambhekar NA, Anchan C, Behle S. Giant cell tumor of bone in children and adolescents. $J$ Pediatr Orthop. 2007;27(6):635-639. doi:10.1097/BPO.0b013e3181425629

13. Kransdorf MJ, Sweet DE, Buetow PC, et al. Giant cell tumor in skeletally immature patients. Radiology. 1992;184(1):233-237. doi:10.1148/radiology.184.1.1609086
14. Jia Q, Chen G, Cao J, et al. Clinical features and prognostic factors of pediatric spine giant cell tumors: report of 31 clinical cases in a single center. Spine J. 2019;19(7):1232-1241. doi:10.1016/j. spinee.2019.02.011

15. He Y, Wang J, Zhang J, Yuan F, Ding X. A prospective study on predicting local recurrence of giant cell tumour of bone by evaluating preoperative imaging features of the tumour around the knee joint. Radiol Med. 2017;122(7):546-555. doi:10.1007/s11547-017-0745-7

16. Murphey MD, Nomikos GC, Flemming DJ, Gannon FH, Temple HT, Kransdorf MJ. From the archives of AFIP. Imaging of giant cell tumor and giant cell reparative granuloma of bone: radiologic-pathologic correlation. Radiographics. 2001;21 (5):1283-1309. doi:10.1148/radiographics.21.5.g01se251283

17. Chakarun CJ, Forrester DM, Gottsegen CJ, et al. Giant cell tumor of bone: review, mimics, and new developments in treatment. Radiographics. 2013;33(1):197-211. doi:10.1148/rg.331125089

18. Krober SM, Greschniok A, Bohm P, Kaiserling E. Giant cell tumor of bone. Morphological, immunohistochemical, morphometric and DNA flow cytometric findings. Verh Dtsch Ges Pathol. 1998;82:279-283.

19. Broehm CJ, Inwards CY, Al-Ibraheemi A, et al. Giant cell tumor of bone in patients 55 years and older: a Study of 34 Patients. Am J Clin Pathol. 2018;149(3):222-233. doi:10.1093/ajcp/aqx155

20. Goldenberg RR, Campbell CJ, Bonfiglio M. Giant-cell tumor of bone: an analysis of two hundred and eighteen cases. $J$ Bone Joint Surg Am. 1970;52:619-664. doi:10.2106/00004623-19705204000001

21. Hoch B, Inwards C, Sundaram M, et al. Multicentric giant cell tumor of bone. Clinicopathologic analysis of thirty cases. J Bone Joint Surg Am. 2006;88:1998-2008.

22. Liu C, Tang Y, Li M, et al. Clinical characteristics and prognoses of six patients with multicentric giant cell tumor of the bone. Oncotarget. 2016;7(50):83795-83805. doi:10.18632/ oncotarget. 13057

23. Dhillon MS, Prasad P. Multicentric giant cell tumour of bone. Acta Orthop Belg. 2007;73(3):289-299.

24. Federman N, Brien EW, Narasimhan V, Dry SM, Sodhi M, Chawla SP. Giant cell tumor of bone in childhood: clinical aspects and novel therapeutic targets. Paediatr Drugs. 2014;16(1):804-808. doi:10.1007/s40272-013-0051-3

25. Howard EL, Gregory J, Winn N, Flanagan A, Cool P. Radiological features of giant cell tumours of bone. Cureus. 2020;12(6):e8793.

26. van den Berg H, Kroon HM, Slaar A, Hogendoorn P. Incidence of biopsy-proven bone tumors in children: a report based on the Dutch pathology registration "PALGA". J Pediatr Orthop. 2008;28 (1):29-35. doi:10.1097/BPO.0b013e3181558cb5
International Journal of General Medicine

\section{Publish your work in this journal}

The International Journal of General Medicine is an international, peer-reviewed open-access journal that focuses on general and internal medicine, pathogenesis, epidemiology, diagnosis, monitoring and treatment protocols. The journal is characterized by the rapid reporting of reviews, original research and clinical studies across all disease areas. The manuscript management system is completely online and includes a very quick and fair peer-review system, which is all easy to use. Visit http://www.dovepress.com/ testimonials.php to read real quotes from published authors. 